\title{
Body-ScanFit ${ }^{\circledR}$ System: Identifying Body Shapes. An Anthropometric Survey Carried Out in 2010 by CME
}

\author{
Giuseppe FIGLIÉ ${ }^{1}$ and Leonardo FRANCESCH ${ }^{2}$ \\ Cad Modelling Ergonomics srl, Italy
}

\section{Introduction}

In the last 20 years, huge demographic changes in terms of immigration, economic crisis but also a diet richer in calories and a more sedentary lifestyle had significant effects on the body shape of people.

Cad Modelling Ergonomics with its advanced anthropometric solutions helps identifying such changes in the conformation of world population. Since 1968.

FORMA $X^{\circledR}$, the fit apparel mannequins developed as the natural result of the Theory of the Body Shapes $^{\odot}$ (copyright SIAE of Cad Modelling Ergonomics num.94018) act as the right tool to guarantee the perfect fit, volume, comfort and safety to garments and ergonomic devices because they are built on real average body shapes worldwide.

The paper will focus on the outcomes of the 2010 anthropometric survey carried out by Cad Modelling Ergonomics on a sample of Italian women between 18 and 35 years and how these data help manufacturers guarantee the right volume and shape to their garments. This survey highlights the most recurrent body shapes in women population thanks to the use of the Body-ScanFit ${ }^{\circledR}$, the only system in the world that features a portable 3D body scanner together with the FX-FIT software, a proprietary web-based application that classifies the subject into the most suitable morphological family.

\section{A changing population}

Since the last Italian manual measurement campaign of the '90s, lots of events had influenced on people's life and behavior: huge immigration, races melting pot, economic crisis but above all an increase of diet calories led to some significant modifications of human body shapes.

A growing percentage of world population is either obese or suffers from diabetes and consequently such metabolic diseases have a great effect on the "conformation": a bigger and more corpulent population is growing faster and faster with lots of needs to satisfy in different sectors: from garments to furniture, from health and medicine to automotive industry.

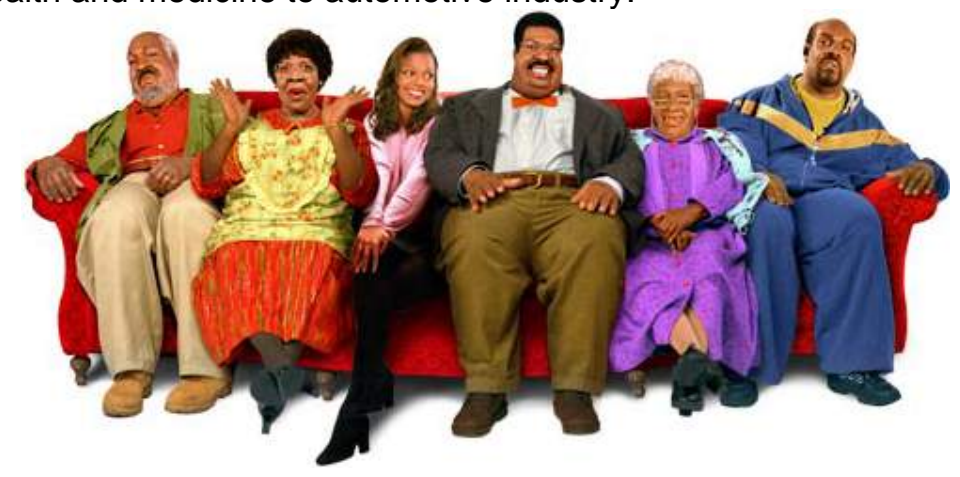

Fig. 1. "Different people with different needs to satisfy"

Catching on these expectations and needs represents an effort each producer has to cope with if he wants to cover this increasing market share.

But how to identify the body shapes and volumes of people correctly and help industries?

Digital technologies like 3D body scanner have nowadays a level of accuracy and precision that allows achieving a true and fair measurement of individuals. Laser-equipped devices are harmless to scan people and permit to perform body assessments in few seconds. But only matching the obtained linear measurements with the Theory of Body Shapes $\odot$ will make the most of these new technologies.

\footnotetext{
${ }^{1}$ Email press@cadmodelling.it Tel. +39 0552476261/2 www.cadmodelling.it

2 Email leonardo.franceschi@cadmodelling.it Tel. +39 0552476261/2 www.cadmodelling.it
} 


\section{Body-ScanFit ${ }^{\circledR}$ system: the only portable 3D body scanner in the world}

Constantly pushing the technology boundaries further, Cad Modelling Ergonomics developed BodyScanFit ${ }^{\circledR}$, a patented system composed of a revolutionary and unique portable body-scanner, validated by ENEA, a primary research institute in Italy. The system allows scanning any human body in few seconds, and classifying it in the proper Morphological Family (also reproduced in Formax ${ }^{\circledR}$ ) to transmit data to the product pipeline.

Body-ScanFit ${ }^{\circledR}$ is based on the first real portable and non intrusive body scanner that fits inside a standard dimensions suitcase. It's easy to set up and user-friendly: Body-ScanFit ${ }^{\circledR}$ can be used also by non technicians.

Through just 4 seconds scanning it assures precision and accuracy, providing useful data that can be used for several applications. Body-ScanFit ${ }^{\circledR}$ is an Anthropometric Classification System that comprehends:

- A unique portable 3D body scanner

- A software for measurements extraction

- A proprietary software for anthropometric classification, the FX-FIT, that highlights the fitting needs of any scanned body and classifies it into the proper body shape.

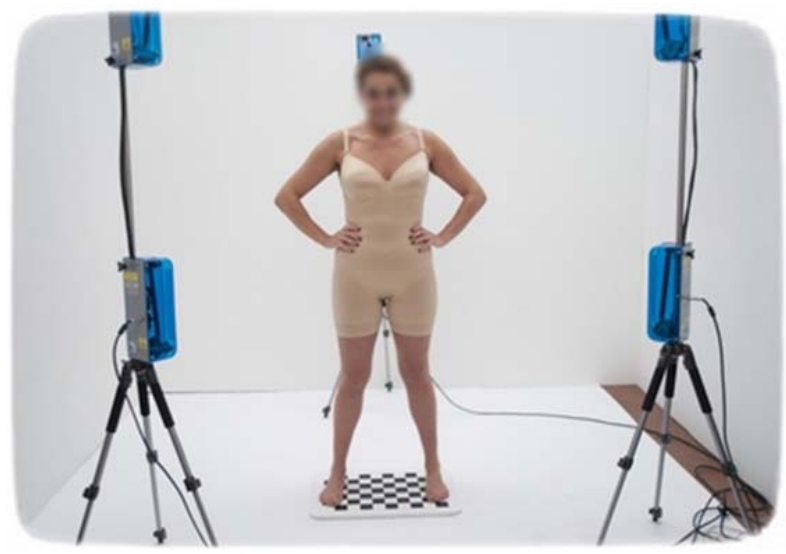

Fig. 2. "The Body-ScanFlit@ system in place"

\subsection{Key system features}

- FAST SCANNING: The system integrates innovative algorithms and harmless laser technologies for a fast acquisition process: 4 seconds are enough to scan any human body, from 80 to $230 \mathrm{~cm}$.

- PORTABILITY: Thanks to years of research and development, the entire system fits in a single suitcase and thus can be easily transported.
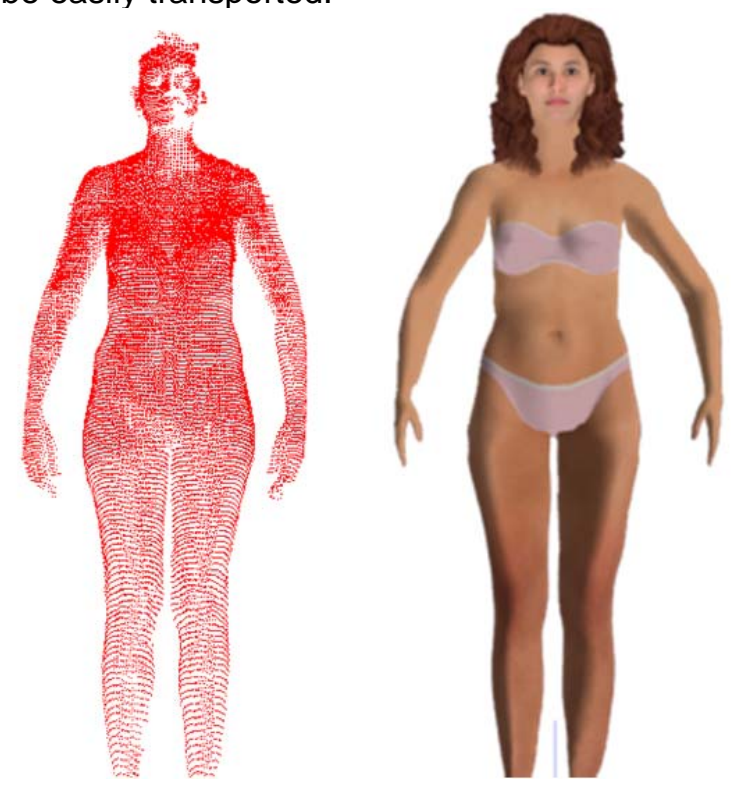

Fig. 3. "Point cloud and avatar of the scanned subject" 
- HIGH ACCURACY AND HIGH QUALITY: The scanning process is extremely accurate and precise (error allowance of $5 \mathrm{~mm}$ ). Thanks to the high quality of the digitization, there is no need to neither change nor improve manually the acquired data.

- FAST INSTALLATION AND USER-FRIENDLY INTERFACE: Body-ScanFit ${ }^{\circledR}$ is installable in less than 10 minutes (including calibration). Assembling, disassembling, calibrating, scanning and all the other functions are simple operations that everybody can afford.

- RAMS: Strength, solidity, availability, reliability, maintenance, safety fully guaranteed. The scanner is designed in order to be assembled and disassembled thousands of times. Every component is carefully tested.

- VERSATILITY: The system runs under Windows XP, Vista, Seven. It can be used with PCs and Laptops equipped with USB and Firewire 400 plugs and generates output files in the mostly used formats. The generated data can therefore be imported in most of the measurement extraction and reverse engineering software, $C A D$, etc.

- LOW-COST, HIGH VALUE: Competitive price in the body scanner market.

- PRIVACY: The scanner assures complete privacy during the acquisition process thanks to the auto scanning procedure through autoscan wire controller.

The system plays an important role in the mass customization of garments and in MTM as well as in the realization of ergonomic products and even in nursery and automotive fields.

\subsection{The linear measurements extraction software}

Body-ScanFit $^{\circledR}$ system also includes linear measurements extraction software that is capable of generating hundreds of dimensions, customizable as per client's targets and needs.

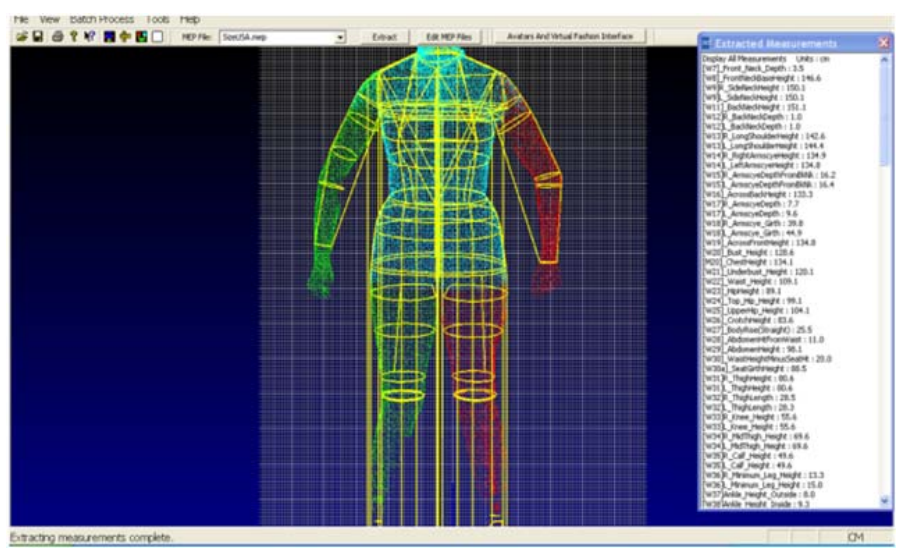

Fig. 4. "200 measures table"

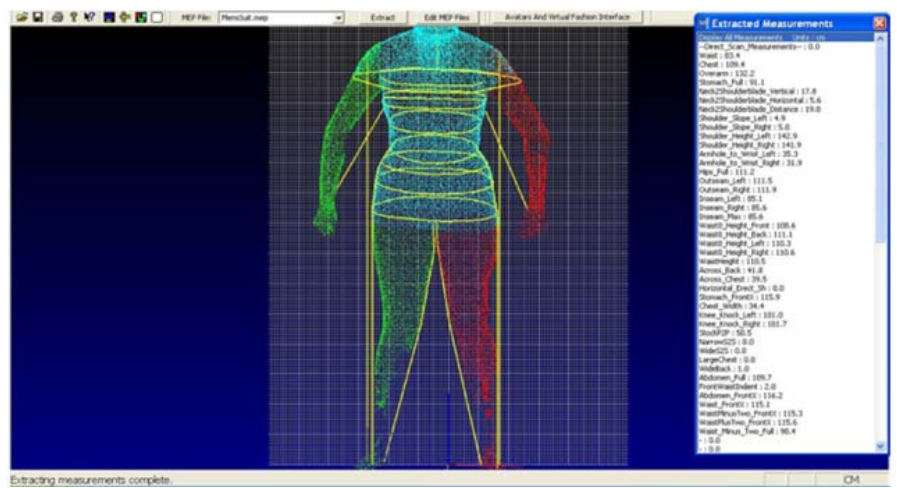

Fig. 5. "50 measures table"

The extracted measurements guide pattern makers and designers in the creation of the right volume and shape for that particular body. 


\subsection{The FX-FIT software: identifying the morphological family.}

Once the subject is scanned and automatically measured, the avatar is loaded into the FX-FIT software, a proprietary web-based application that classifies the person into the most suitable morphological family.

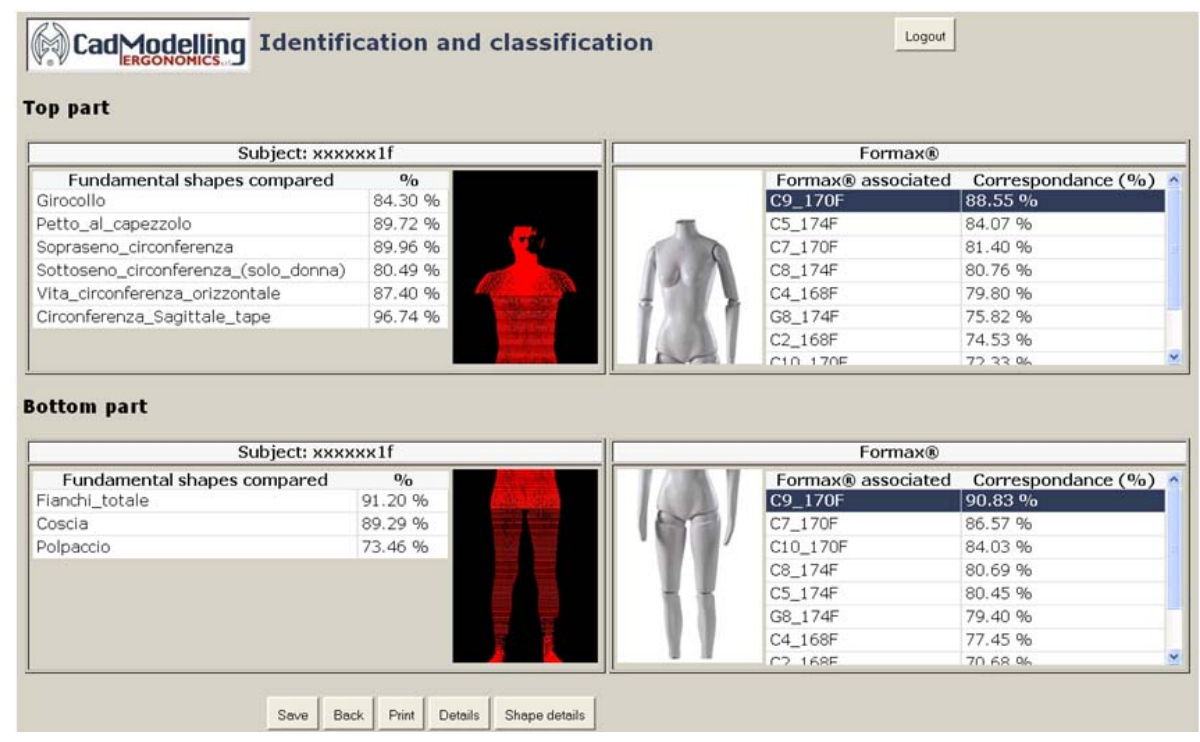

Fig.6. "FX-FIT software"

The software performs a comparison with Cad Modelling Ergonomics' anthropometric database both for the upper and the lower part of the body. Such application leverages the Theory of Body Shapes $\odot$ (Copyright @ SIAE $n^{\circ} 9401846$ of Cad Modelling Ergonomics) that states that each man and woman in world can be classified into recurrent conformations: 7 for men and 11 for women.
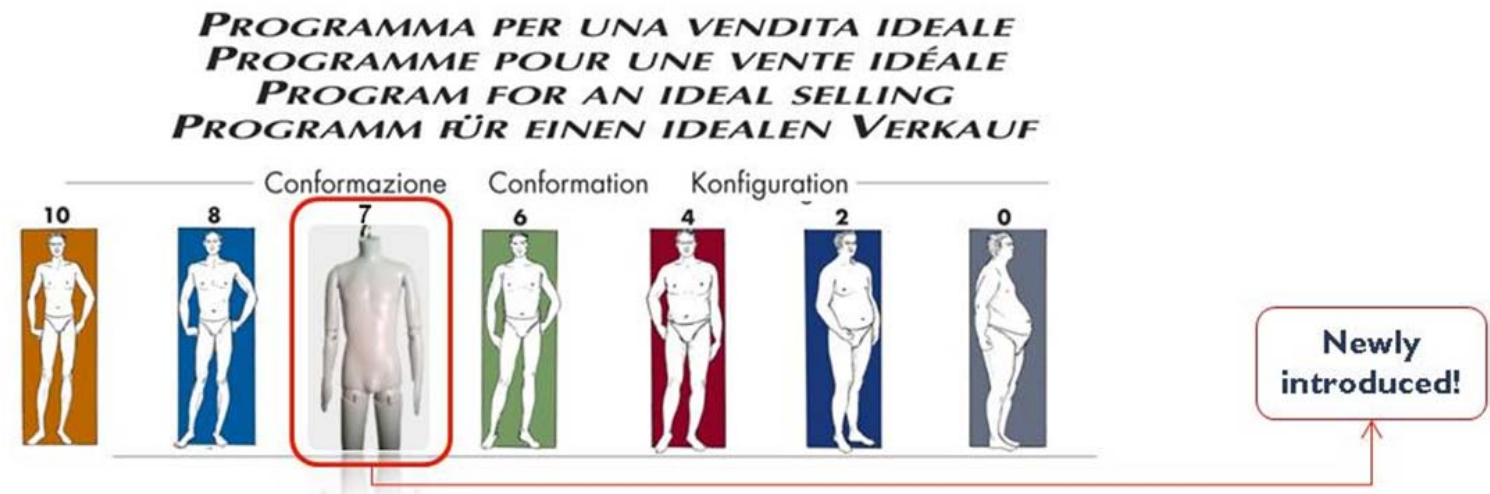

Fig. 7. "Man conformations"

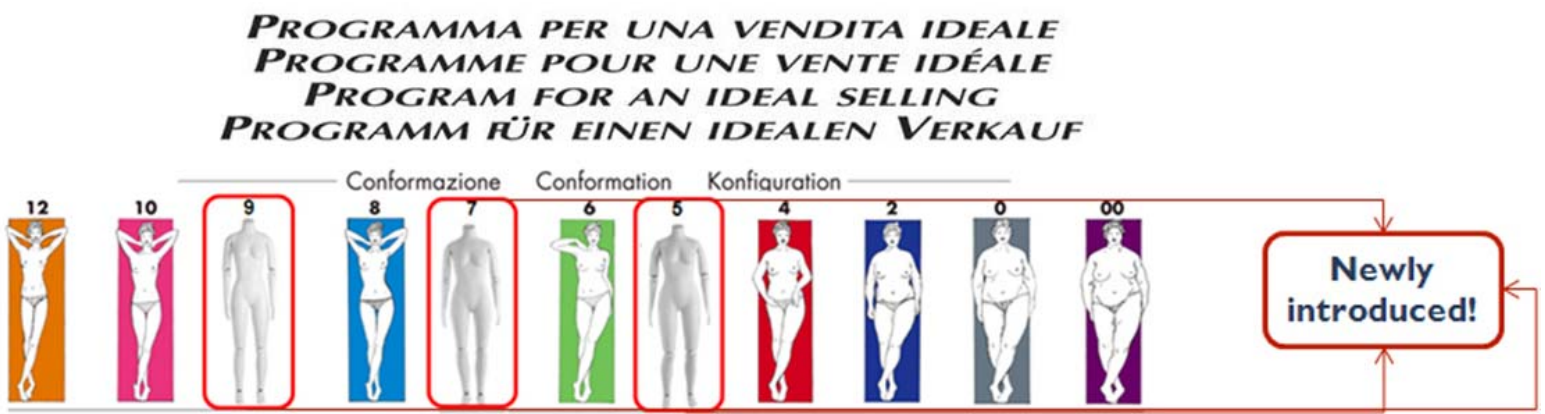

Fig. 8. "Woman conformations"

The FX-FIT software returns also a complete data sheet with all the basic measurements (Fig. 9) of the scanned subject. Below, you find the most suitable conformation both for the upper and the lower 
part of the body, developments included. This $360^{\circ}$ approach gives precious information to garments producers as well as ergonomic devices producers, in order to obtain the right fit and comfort for each particular body volume.

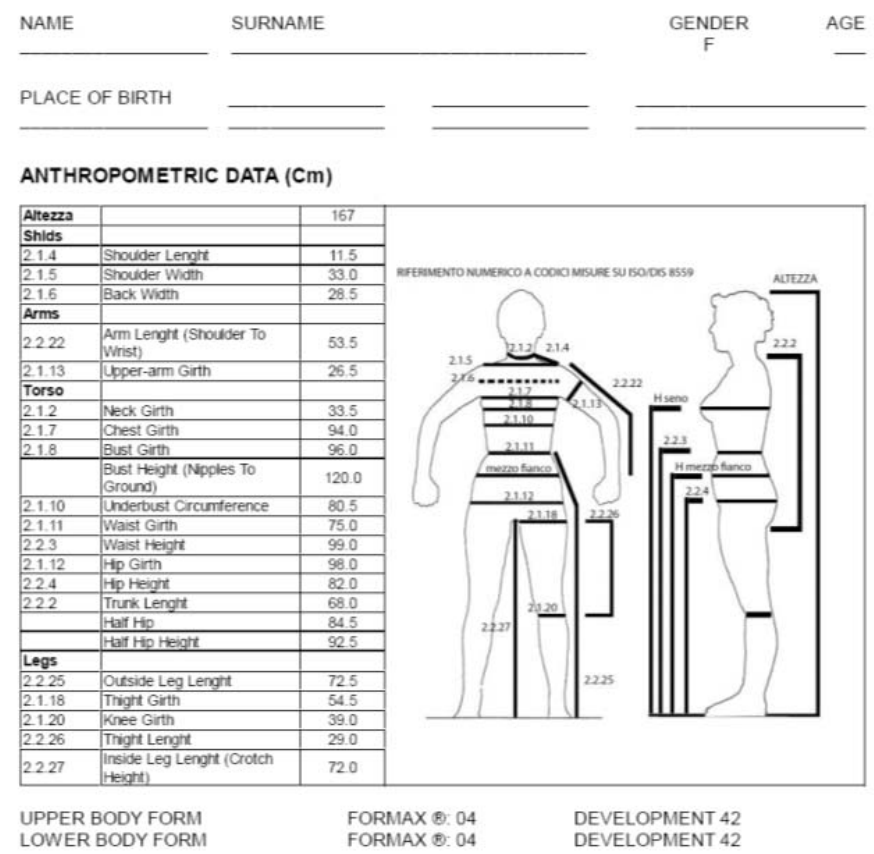

Fig. 9. "Personal data sheet"

As population is constantly changing, the Theory of Body Shapes $\odot$ gives again the solution in terms of starting point and grading rules. Thanks to recurring anthropometric surveys to constantly match real people, the morphological families are thus improved and updated.

In the sample of Italian women that was monitored in 2010 by Cad Modelling Ergonomics, the FX-FIT software was the key to identify such recurrent/new body shapes and new evolving trends.

\section{Identifying body shapes: an anthropometric survey carried out by Cad Modelling Ergonomics in 2010}

Italian population has faced huge demographic changes in the last decades due to several factors (immigration, high calorie diet, sedentary lifestyle etc). These social modifications had significant effects on the body shape of people. Catching on these changes is really important for lots of manufactures: in fact, the better knowledge of the volumes and shapes of people will help industries satisfy the needs of a more and more demanding population.

\subsection{Objectives and targets}

The aim of the survey, carried out in 2010 on a sample of $\sim 900$ Italian ladies between 18 and 35 years, was to improve the comfort and the fit of workwear and corporatewear and decrease the unsold stocks as well as the returns.

In particular, the customer wanted to increase the safety of corporatewear and workwear in every situation, increasing also the look \& feel and the comfort of the garments.

\subsection{Survey procedures}

The sample was monitored and measured along 2010, in 6 months, through 15 sites in Italy to guarantee the right cover of the nation. Each site was equipped with a Body-ScanFit ${ }^{\circledR}$ system operated by a team of Cad Modelling Ergonomics' experts. This was the first campaign carried on with 3D body scanner like Body-ScanFit ${ }^{\mathbb{Q}}$ system. The Italian anthropometric campaign of the '90s was performed with manual measurements with tailor tapes.

To maintain a tight agenda of scans, 10 to 80 subjects were scanned daily with one scan per subject. This allowed shrinking the time frame of the entire survey and returning the outcomes to the customer in a short period of time. 
The procedure of the measurement was the following:

- Scan of the subject and point cloud creation

- Linear measurements extraction

- Classification into the most suitable morphological family by FX-FIT

- Identification of the corresponding FORMAX ${ }^{\circledR}$ for the upper and lower part of the body

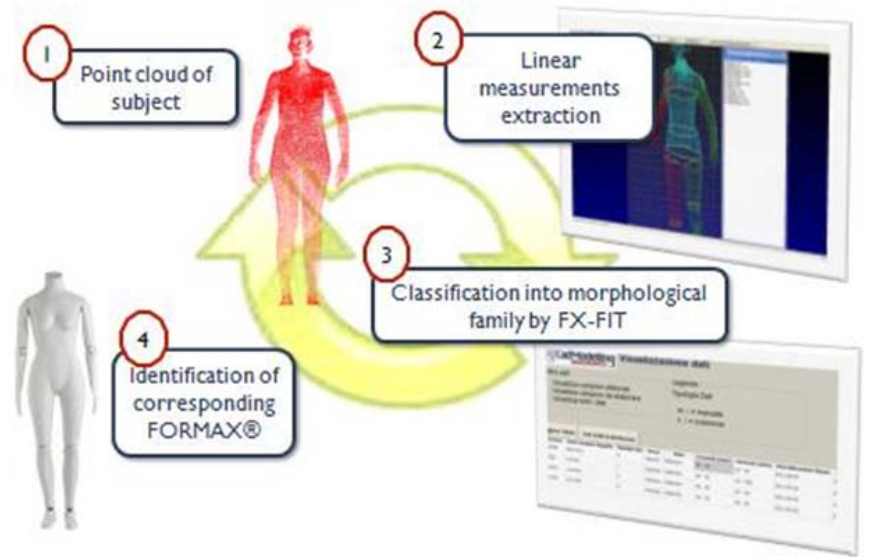

Fig. 10. "Survey procedures"

\subsection{A more robust woman conformation}

As seen from the graphics below, the most recurrent conformations both for the upper and lower part of the body were number 5 (new robust) and number 8 (harmonious) with a prevalence of the first. This confirms that woman body shape has slightly increased since the last campaign of the '90s.

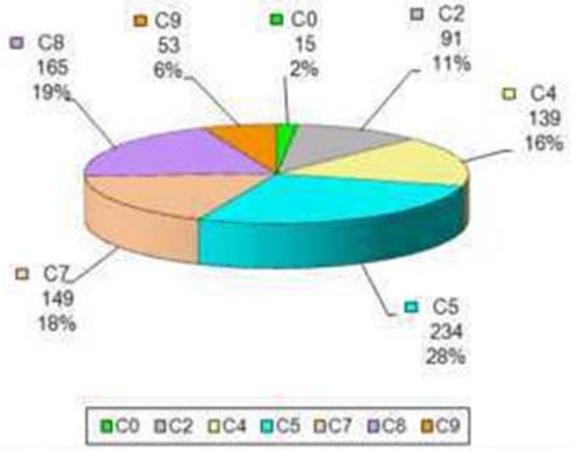

Fig.11. "Upper part of conformation"

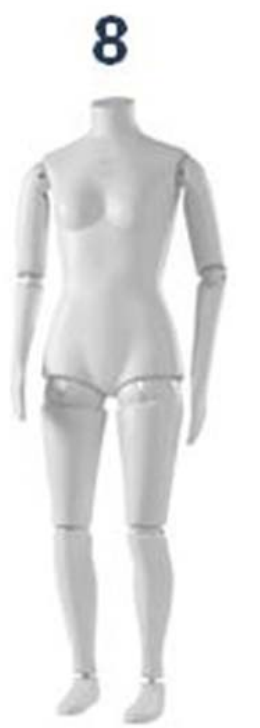

Fig.13. "Woman conformation 8"

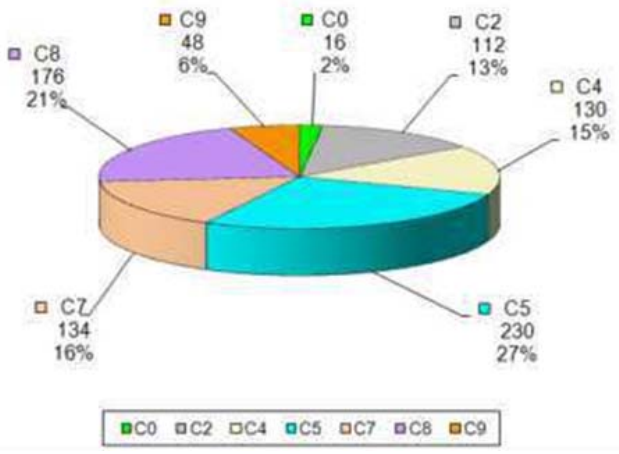

Fig. 12. "Lower part of conformation"

5

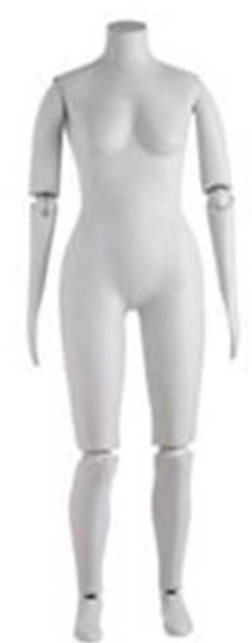

Fig. 14. "Woman conformation 5" 


\subsection{Customizable Data}

Collected survey data can be highly customizable since they can be put together in different charts following company targets: the manufacturers have now the opportunity to perform any type of analysis to better understand their customers' needs and expectations.

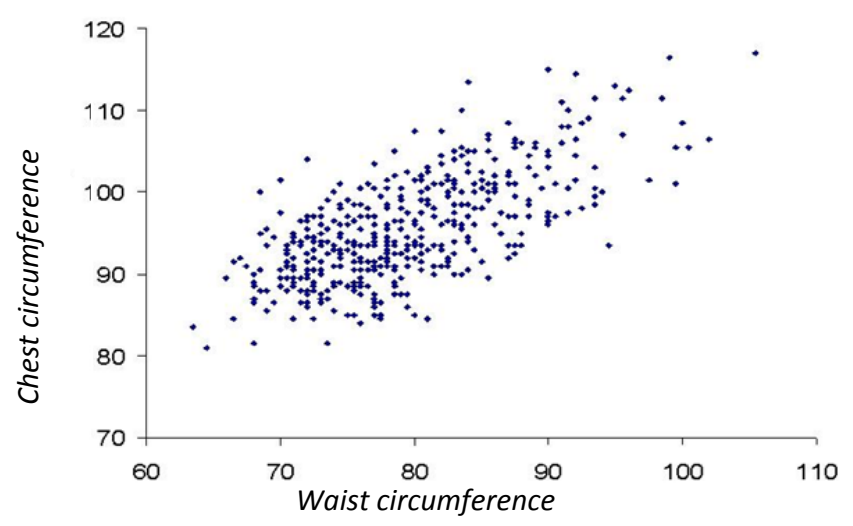

Fig. 15. "Chest-waist table. Scattered data"

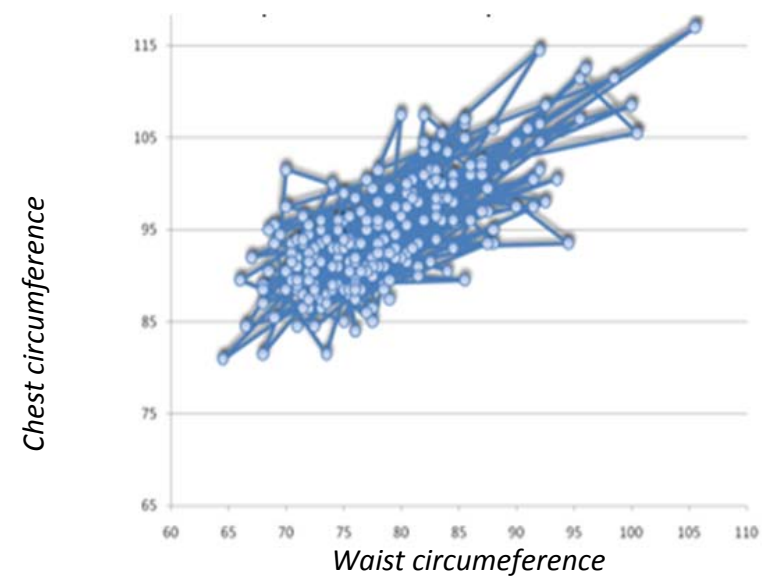

Fig. 16."Chest-waist table by height 160-167 cm"

As seen from the image below, the outcomes show that the height range $160-167 \mathrm{~cm}$ was the most recurrent in the monitored sample.

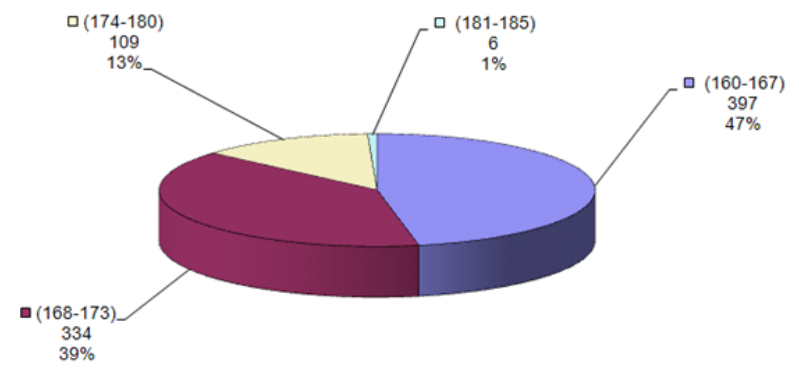

$\square(160-167) \quad \mathbf{\square}(168-173) \quad \square(174-180) \quad \square(181-185)$

Fig. 17. "Most recurrent height range in the sample: distribution." 
The opportunity to customize the data of the survey was another key to success because this great flexibility is required by companies everyday more and more, and everyone has different and specific requirements and consequently different used data and useful weights for the analysis.

In the table below, you may see CME suggestion for changing customer's height ranges, on the basis of the 2010 anthropometric survey that made a realistic snapshot of the customer base:

Table 1. "Comparison of customer and sample height ranges"

\begin{tabular}{|c|c|c|c|}
\hline \multicolumn{2}{|c|}{ CUSTOMER RANGE } & \multicolumn{2}{c|}{ POST CAMPAIGN PROPOSAL } \\
\hline $\begin{array}{c}\text { Range h } \\
(\mathrm{cm})\end{array}$ & DEFINITION & $\begin{array}{c}\text { Range h } \\
(\mathbf{c m})\end{array}$ & DEFINITION \\
\hline $160-167$ & Range A & $\mathbf{1 6 0 - 1 6 5}$ & Range A \\
\hline $168-173$ & Range B & $\mathbf{1 6 6 - 1 7 1}$ & Range B \\
\hline $174-180$ & Range C & $\mathbf{1 7 2 - 1 7 8}$ & Range C \\
\hline $181-185$ & Range D & $\mathbf{1 7 9 - 1 8 5}$ & Range D \\
\hline & & & \\
$>185$ & TAILOR-MADE & $\mathbf{> 1 8 5}$ & TAILOR-MADE \\
\hline
\end{tabular}

The table represents how anthropometric data act as a precious support for all manufacturers willing to mass customize their production and consequently decrease the percentage of unsold stocks, that weight up to $30 \%$ on company's turnover.

\subsection{Shapes and Developments}

The average development of each conformation is the so called "normotype" of that particular morphological family. It acts as a starting point to grade up and grade down by using mathematic proportions for shapes and volumes

Grading is the process of developing the garment by increasing or decreasing the shape and the volume of the apparel proportionally. This process is known as "size grading" in clothing textile industry; this well known procedure is however correct only if related to the basis of the real anatomy (conformation and its developments), that is always the starting point.

Grading in this way is the key for all the pattern makers that want to guarantee the perfect fit and comfort.

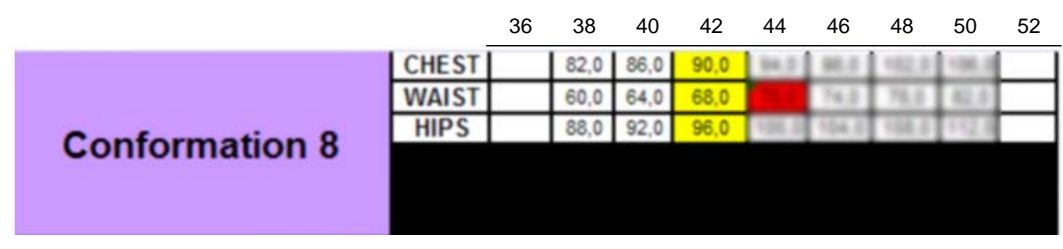

Fig. 18. "Conformation 8 and its grading. Body measurements"

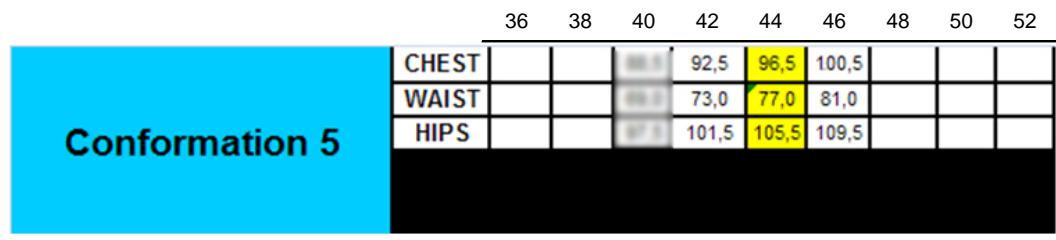

Fig. 19 "Conformation 5 and its grading. Body Measurements" 


\subsection{Population distribution in developments of Conformation 7 - Woman}

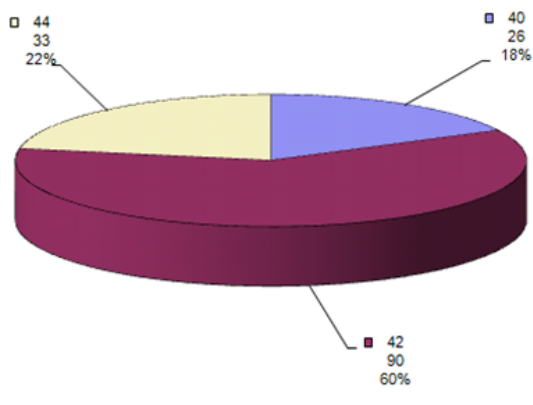

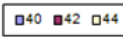

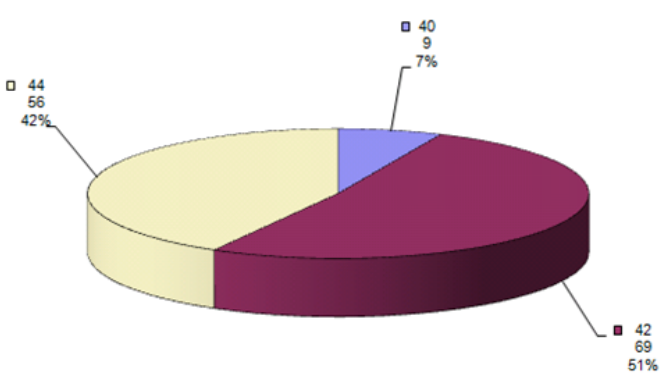

$040 \quad \mathbf{0 4 2} \quad 044$

Fig. 20. "Sample distribution in developments of Conformation 7"

\begin{tabular}{c|c|c|c|c}
\multirow{2}{*}{$\begin{array}{c}\text { Conformation } 7 \\
\text { TOTAL }\end{array}$} & \multicolumn{3}{|c|}{ UPPER PART } & \\
\cline { 2 - 5 } & 40 & 42 & 44 & TOTALS \\
\hline RANGE A & 15 & 38 & 16 & 69 \\
\hline RANGE B & 8 & 43 & 15 & 66 \\
\hline RANGE C & 3 & 9 & 2 & 14 \\
\hline RANGE D & 0 & 0 & 0 & 0 \\
\hline TOTALS & 26 & 90 & 33 & 149
\end{tabular}

\begin{tabular}{|c|c|c|c|c|}
\hline \multirow{2}{*}{$\begin{array}{c}\text { Conformation } 7 \\
\text { TOTAL }\end{array}$} & \multicolumn{3}{|c|}{ LOWER PART } & \multirow[b]{2}{*}{ TOTALS } \\
\hline & 40 & 42 & 44 & \\
\hline RANGEA & 7 & 31 & 28 & 66 \\
\hline RANGE B & 2 & 31 & 21 & 54 \\
\hline RANGE C & 0 & 7 & 7 & 14 \\
\hline RANGE D & 0 & 0 & 0 & 0 \\
\hline TOTALS & 9 & 69 & 56 & 134 \\
\hline
\end{tabular}

Fig. 21. "Sample distribution in grading and height range in Conformation 7 - woman"

Conformation 7 stands between the most recurrent conformations found in the last survey, covering by itself $17 \%$ of the population. In case the apparel brand wishes to choose just a single normotype for the entire development of the collection, the customer is strongly helped in his sub-choice by using Grading/Height Range Tables, as shown in picture 21.

\subsection{Mass Customization final steps and use of Formax ${ }^{\circledR}$ mannequins}

As previously said, the data are fully customizable following client's needs.

Garments manufacturers often create products on the basis of marketing analyses and statistics that do not fully match people's real volumes and body shapes. The process of data analysis is the key for the best mass customization choices (money saving) and the best results in terms of right fitting and comfort (final user's satisfaction).

The mass customization of products was optimized by eliminating the conformations that weren't so recurrent in the monitored sample and then identifying other possible grading of the most frequent body shapes.

This operation led to the identification of the corresponding FORMAX ${ }^{\circledR}$ needed for garment production, fitting and quality control (all the main steps of pipeline). FORMAX ${ }^{\circledR}$ are the only fit apparel mannequins that guarantee the right fit, volume and comfort to the garments. Huge benefits in terms of unsold stocks decrease and improved customer's loyalty are some of the advantages a customer can get out of an anthropometric survey like Cad Modelling Ergonomics' 2010 one.

Anthropometric mannequins like FORMAX ${ }^{\circledR}$, in fact, allow to:

- Constantly check collection prototypes

- Get the right fit, comfort and volume of garments

- Correctly design ergonomic devices

- Test technical textiles in the wind and rain tunnels

because they are real anatomies built on average world body shapes. 


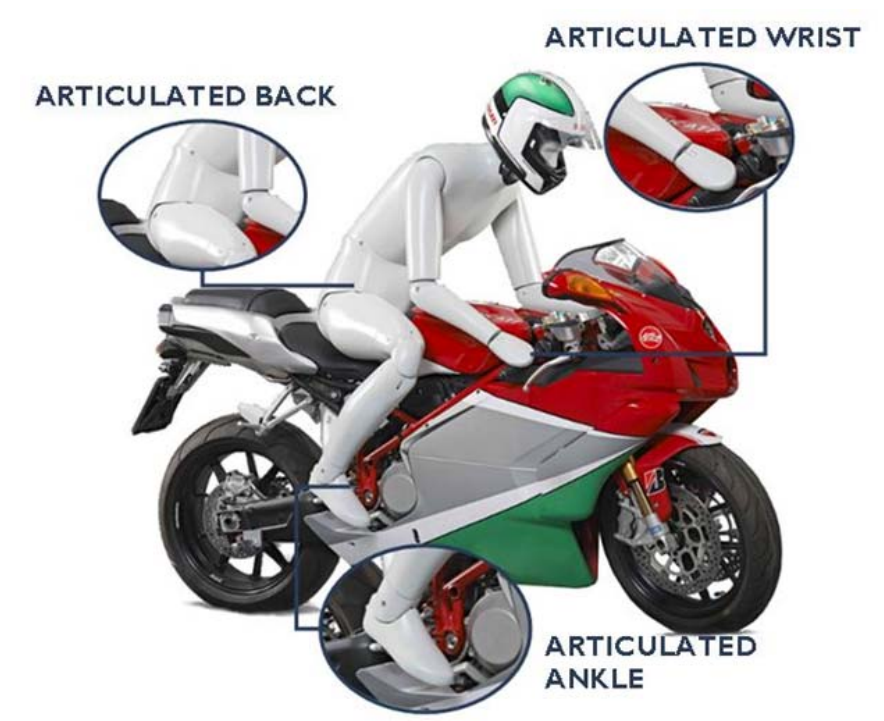

Fig. 22. "SuperActive FORMAX $X^{(B)}$ for ergonomic and safety tests"

\subsection{Survey outcomes}

Thanks to the identification of the recurrent volumes and body shapes of sample, the customer was capable of creating corporatewear and workwear with a higher degree of comfort, fit and safety that was not guaranteed by previous garments.

The survey consequently helped customer optimize the purchasing activities at all levels.

The Theory of Body Shapes ${ }^{\odot}$ and FORMAX® are copyrights and patents of Cad Modelling Ergonomics srl. Any unauthorized use prohibited.

\section{Bibliography}

Quattrocolo S., METODO PER PROGETTISTI PER L'INDUSTRIA DELL' ABBIGLIAMENTO, Cad Modelling Ergonomics srl 1987

Quattrocolo S., ELECTRONIC IMAGING OF THE HUMANY BODY, CSEIAC, 1992

Cad Modelling Ergonomics srl, Theory of Body Shapes ${ }^{\circ}$ (Copyright (c) SIAE n ${ }^{\circ} 9401846$ )

Cad Modelling Ergonomics srl, patent EP1244367

Cad Modelling Ergonomics srl patent EP0634114B1 